\title{
Registration procedure of generic drugs in the Republic of Kazakhstan and Europe: Review
}

\author{
Dinara Kaliyeva, Assiya Turgambayeva, Zakira Kerimbayeva \\ ${ }^{I}$ Department of Public Health and Management, Astana Medical University, Nur-Sultan, Kazakhstan
}

Received: 2021-11-05.

Accepted: 2022-02-07

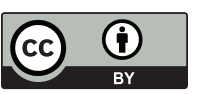

This work is licensed under a Creative Commons Attribution 4.0 International License

J Clin Med Kaz 2022; 19(1):23-27

Corresponding author:

Dinara Kaliyeva.

E-mail: de.kaliyeva@gmail.com;

ORCID: 0000-0001-8231-7965.

\begin{abstract}
Before medicines enter the pharmaceutical market of the Republic of Kazakhstan, the applicant must pass the registration procedure. The process of registration of medicines is necessary to provide the population of Kazakhstan with high-quality, effective and safe medicines, which, in turn, will lead to an improvement in the general health of the population.

The study of the registration process of generic medicines is an urgent problem for practical healthcare, which causes scientific and practical interest in this issue and serves as the basis for this study.

The search for health policy literature was carried out on the official websites: www.who.int, www.ndda.kz, www.ema.europa.eu and the search for scientific publications was carried out in the search engines: PubMed, GoogleAcademia, eLibrary.ru, Cyberleninka.

Further scientific developments in this direction will be of particular relevance and will allow not only to give a comparative description of the registration process of generic medicines, but also to develop recommendations for its improvement.

Key words: drug, generic, medicines, regulatory requirements, registration process, Republic of Kazakhstan
\end{abstract}

\section{Introduction}

One of the most effective measures to reduce the cost of medicines for both healthcare and patients is the use of generics.

Generics have additional social value that exceeds their potential for savings through price reductions. Generics are expanding access to pharmacotherapy, creating an incentive for innovation by both manufacturing and generic companies, and, under certain circumstances, positively impacting adherence to treatment [1].

According to various research low awareness of generic drug characteristics and the reluctance of healthcare providers to prescribe generics have a significant negative impact on the rational use of more affordable generic drugs. It is imperative that doctors and pharmacists correctly understand the characteristics of generics and provide patients with complete and detailed information. An important factor in increasing trust in generic medicines is the provision of complete information about drug regulation, equivalence [2].

Before the medicines enter the pharmaceutical market of the Republic of Kazakhstan, the applicant must pass the registration procedure. The process of registration of medicines is necessary to provide the population of Kazakhstan with high-quality, effective and safe medicines, which, in turn, will lead to an improvement in the general health of the population.

The study of the registration process of Generic drugs is an urgent problem for practical healthcare, which causes scientific and practical interest in this issue and serves as the basis for this study.

The purpose of the study was to compare generic drug registration process in the Republic of Kazakhstan and European Union countries and to find out the differences, lacunae among the regulatory requirements.

\section{Material and methods}

The search for health policy literature was carried out on the official websites: www.who.int, www.ndda. kz, www.ema.europa.eu and the search for scientific publications was carried out in the search engines: PubMed, GoogleAcademia, eLibrary.ru, Cyberleninka.

Inclusion criteria: Due to the importance of revealing the historical sequence of the regulation of generics, the search depth was 10 years (1 January, 2011 to 1 December, 2021). Publications in Kazakh, Russian and 
English were included, health policy literature and full-text research. Preference was given to high-quality works, such as systematic reviews, meta-analysis. The study was carried out by searching for keywords: Drug, Generic, Medicines, Regulatory Requirements, Registration Process and Republic of Kazakhstan.

Exclusion criteria: publications of low methodological quality that did not reflect the main significance, with unclear and ambiguous conclusions, studies, recurrent publications.

As a result of the search, we identified only 350 foreign and domestic publications. Of these, 15 publications were included in this review, taking into account the inclusion and exclusion criteria. The selection algorithm is shown in Figure 1.

Figure 1 - Algorithm for selecting scientific publications

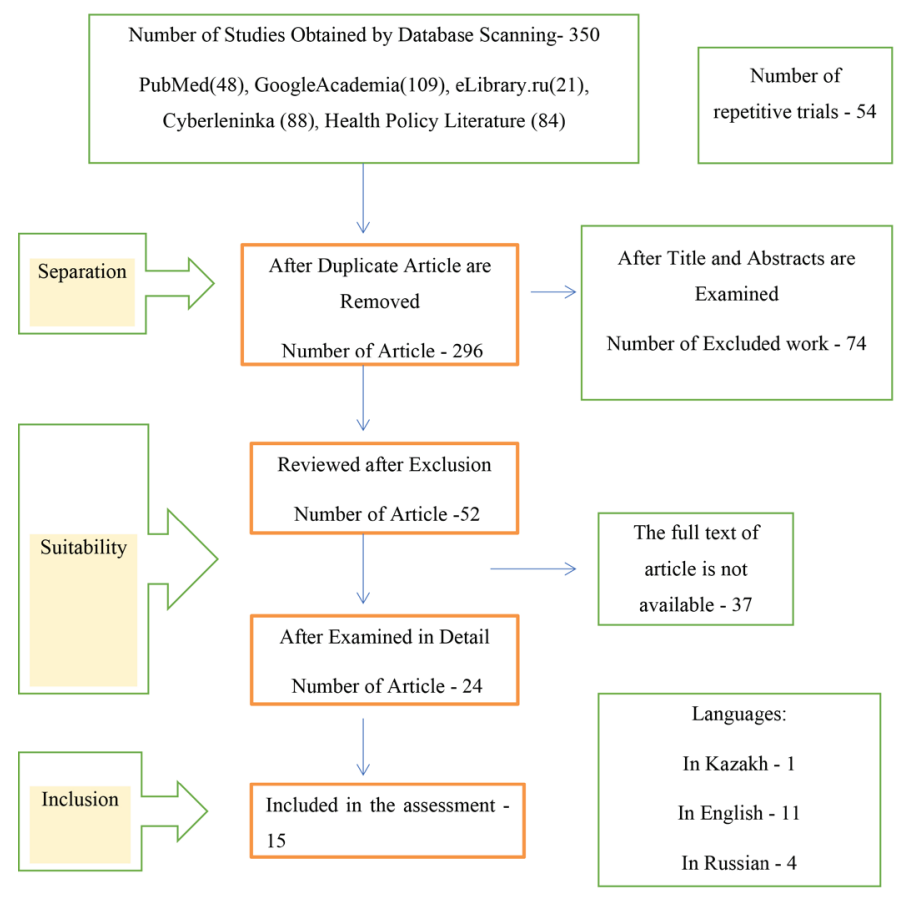

\section{Results and discussion Characteristics of Generic Drugs}

Medicinal products are conventionally divided according of development into originator medicinal products and generics.

The term "Generic" may have different definitions depending on the country. These definitions are of decisive importance for national agencies of states and determine the scope of requirements for the registration dossier for the state registration of a generic drug. According to the WHO definition: «A pharmaceutical product usually intended to be interchangeable with the originator brand product, manufactured without a license from the originator manufacturer and marketed after the expiry of patent or other exclusivity rights» [3].

Generics are medicinal products, the production of which is possible after the expiration of patent protection for the original drug of the innovator's company. As a rule, pharmaceutical companies have the right of a patent holder for a period of 20 years to justify the resources expended [4].

WHO definition: Originator (innovative) pharmaceutical product - generally the product that was first authorized worldwide for marketing (normally as a patented product) on the basis of the documentation of its efficacy, safety and quality, according to requirements at the time of authorization [5].

Currently, the average cost of generic drugs is about $80 \%$ cheaper than the original drugs, have a lower cost due to fewer resources for developing a medicine.

The development of innovative medicine is aggregate, expensive and time-consuming long- term work, the development time can take up to 10 -15 years, and the cost can range from 800 to 2 billion United States (US) dollars higher [6].

The development of innovative medicines includes:

- The discovery of a molecule

- Preclinical development, first in vitro tests, then in vivo laboratory studies on animals, assessment of the pharmacological effect, mutagenicity, toxicity, teratogenicity, etc.

- Clinical trials. Once approved by the appropriate regulatory authority to introduce an innovative medicine, clinical trials can begin.

The clinical trials required to bring a new drug to market usually take place in three phases. In the first phase, the safety profile of the new drug for humans is studied. Typically is performed on healthy volunteers. After the successful completion of the first phase of clinical research, the second phase is started. Studies are conducted in the target population / patients. The main objective of these studies is to determine the effectiveness of a new drug in comparison with existing alternative therapies or placebo. The third phase, as a rule, is large-scale, multicenter studies, comparative studies on a large number of patients. The main goal of these studies is to confirm the safety and efficacy of a new drug. Based on the data obtained in the current of the study, a conclusion is made for the risk- benefit profile of the new medicine [7].

For generics, there is no need for extensive preclinical and clinical development, before entering the pharmaceutical market the generic confirms its equivalence to the original medicine by appropriate bioavailability studies [8].

\section{Comparison Drug Registration Procedures in the Republic of Kazakhstan and Europe}

In the Republic of Kazakhstan, medicines are used only if they are registered. The types of drug registration are registration, re-registration and variations. Re-registration and variations are procedures available after registration of a medicine and obtaining a registration certificate. Re-registration is required to confirm authorization upon the expiration of the registration certificate after five years. Variations are made in case of changes that relate to the quality, safety and efficacy of medicines.

The registration procedure is required for the admission of medicines to the pharmaceutical market. The Registration Certificate is issued on the basis of quality, efficacy and safety then the medicine is introduced in the State Register of Medicines and Medical Devices of the Republic of Kazakhstan. The expertise of all pharmaceutical products quality, efficacy and safety is done by Republican State Enterprise with the Right of Economic Management «National Center for Expertise of Medicines and Medical Devices» (National Center). Applicants for registration of medicines submit registration dossier directly to National Center. Upon completion of the examination of the quality, effectiveness and safety of pharmaceutical products at the National Center, expert assessments are submitted to the Committee for medical and pharmaceutical control (Committee) than Committee takes the decision to register the product and issues Registration Certificate [9].

Until recently, two procedures for registration of medicines operated in parallel in the Republic of Kazakhstan: the national procedure for registration of medicines and registration of medicines within the Eurasian Economic Union (EAEU or Union)). 
In 2014, the member states of the Eurasian Economic Union signed the Treaty on the Eurasian Economic Union. The member states are five countries: Russia, Kazakhstan, Kyrgyzstan, Armenia and Belarus. The Union also has observers from Uzbekistan, Cuba and Moldova. The Agreement on the Circulation of Medicines of the Union (Agreement) was concluded by the Member States on December 23, 2014. In 2015, the Union began its work, but the common drug market began to function a little later, which was due to the need to adopt a number of rules. The rules provided by the Agreement are requirements, guidelines, procedures and instructions.

The first drug registered in accordance with the rules of the Union, Triumeq (Abacavir + Dolutegravir + Lamivudin), filmcoated tablets manufactured by Glaxo Operations UK Limited, United Kingdom, was registered in 2018 in the reference state of the Republic of Kazakhstan. Nowadays, registration within the EAEU is routine.

To date, the only available procedure for registration of medicines in the EAEU member states is registration within the Union. The national procedure for registration of medicines in the Republic of Kazakhstan was completed on July 1, 2021. Total 7,479 medicines (as of November 9, 2021) were registered in the State Register of the Republic of Kazakhstan according to the national procedure [10]. According to the unified rules of the Union, the Unified Register of which included 672 medicines (as of November 13, 2021) [11].

Medicines registered in the EAEU member states must be brought in line with the requirements and rules of the Union by the end of 2025. The transitional period will end on January 1, 2026, and all drug registration certificates issued in accordance with the national legislation of Kazakhstan will be canceled.

In general, the legislation in the field of drug regulation of the Republic of Kazakhstan is harmonized with the Eurasian Economic Union rules. European Union regulatory documents are a prototype of the Union rules [9].

In Europe, marketing authorization is applied for with European medicine agency (EMA). In the European Union, there are three procedures available for authorizing medicines: Centralized procedure (CP), Decentralized procedure (DCP) or Mutual recognition procedure (MRP). In some Member States, a national procedure has been maintained according to which a medicine is registered in accordance with the legislation of that Member State.

$\mathrm{CP}$ is required for innovative drugs, drugs for the treatment of AIDS, neurodegenerative disorders, orphan drugs, drugs for cancer, or diabetes, as well as drugs derived from biotechnological processes. An application for registration of a drug is submitted directly to the EMEA secretariat, if the Eurocomission decides to register a drug, the drug is marketed throughout the EU [12].

The MRP can be initiated if, at the time of application, the drug is already registered in one of the EU countries. The country in which the first registration in the EU is obtained is the reference country. The procedure is based on the principle of mutual recognition of the EU member states. An application for an MRP can be submitted to one or more member states. Registration in the reference country takes 210 days then in case of a positive decision, copies of the report prepared by the experts of the national agency of the reference country are sent to the Member States to which the MRP application was submitted. The decision on registration is made by the national agencies of the EU Member States. Within 90 days, the recognition states make decisions on the basis of the report submitted by the reference state. National marketing authorizations go beyond registration deadlines and take 30 days from [13].
With DCP, an application is submitted simultaneously to several national agencies of the EU countries, one of which is selected as a reference. It is carried out if the drug has not previously been registered in any of the EU countries. The decision on registration is taken by the national agencies of the EU member states [14].

Only two types of registration procedures are available in the Union: the «Mutual Recognition Procedure» and the «Decentralized Procedure». The registration process is shown in Figure 2.

Figure 2 - Registration Procedures for Medicines in the EAEU

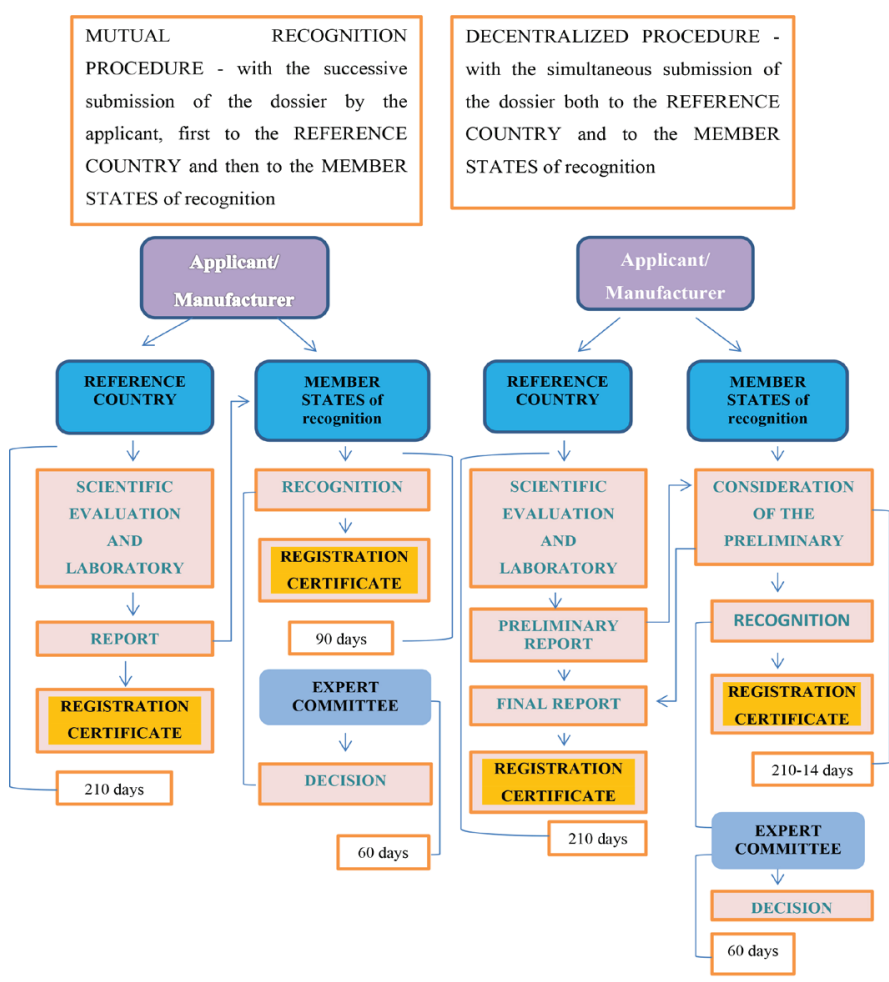

Both procedures can be used for registration of original medicines, generic pharmaceuticals, hybrid medicines, medicines with well-studied medical applications, combined medicines, biosimilars, biological medicines, radiopharmaceuticals, homeopathic medicines, herbal medicines, high-tech medicines. The decision of the Council of the Union of November 3, 2016 No. 78 (Decision No. 78) is the legal basis for registration procedures and the life cycle of medicinal products in the Union.

Although the regulatory documents of the European Union are a prototype of the EAEU rules, we see significant differences in the registration procedures of medicines in the Union and the EU, as shown in Table 1.

\section{Table 1 \\ Differences between MRP and DRP in the EU and the Union}

\begin{tabular}{|l|l|}
\hline EU & UNION \\
\hline $\begin{array}{l}\text { A clear requirement to initiate a } \\
\text { MRP or DSP }\end{array}$ & No clear requirement \\
\hline $\begin{array}{l}\text { Affiliated companies recognize } \\
\text { the same the company, therefore, } \\
\text { parallel statements are not allowed }\end{array}$ & $\begin{array}{l}\text { There is no restriction on filing } \\
\text { applications for one the same drug } \\
\text { by affiliated companies }\end{array}$ \\
\hline $\begin{array}{l}\text { The company and the regulator are } \\
\text { discussing the date filing }\end{array}$ & $\begin{array}{l}\text { Discussion not provided, absent } \\
\text { time limits for submission of } \\
\text { applications }\end{array}$ \\
\hline $\begin{array}{l}\text { As such, Registration is not } \\
\text { provided }\end{array}$ & $\begin{array}{l}\text { The meaning of the Registration } \\
\text { procedure is not clear, and the } \\
\text { difference from DSP }\end{array}$ \\
\hline $\begin{array}{l}\text { National stage over the procedure } \\
\text { (+30 days) }\end{array}$ & National stage within the procedure \\
\hline
\end{tabular}


There is no clear requirement in EAEU to initiate MRP or DCP. It remains unclear what is the fundamental difference between registration according to the MRP and DCP procedure in Union.

In addition, the EAEU does not provide for either national or centralized procedures.

For the registration of medicines, the registration dossier is submitted to the Authorized body (Expert organization) of the Member State, the registration dossier is subject to scientific assessment for quality, safety, efficacy and tolerability. Registration dossier of medicines is provided in the format of a Common technical document in accordance with part I Appendices 1 of Decision № 78. The general Requirements for the Materials of the Registration Dossier are given in Table 2.

Table 2

The General Requirements for the Materials of the Registration Dossier

\begin{tabular}{|l|l|}
\hline REFERENCE COUNTRY & MEMBER STATES of recognition \\
\hline - Completed application form & - Completed application form \\
(paper and (or) electronic) & (paper and (or) electronic) \\
- Proof of payment of duties / fees & - Proof of payment of duties / fees \\
- Modules I-V (electronic) & - Module I (paper and (or) \\
- Samples of the finished product & electronic) \\
for laboratory testing & - Reference state report \\
& - Samples of SmPC, LP, labeling in \\
& the official language of the state of \\
& recognition (if applicable) \\
\hline
\end{tabular}

\section{Requirements for Generic Drugs}

The registration dossier of the generic medicinal product is submitted in accordance with of Section 6, Part II of Appendix 1 of Decision No. 78.

The bioequivalence of the generic to the original medicinal product must be demonstrated by appropriate comparative bioavailability studies in accordance with the Decision of the EAEU Council of November 3, 2016 No. 85 (Decision No. 85). Differences in the requirements for the Materials of the Registration Dossier for Original Medicines and Generics are shown in Table 3.

Differences in the requirements for the Materials of the Registration Dossier for Original Medicines and Generics

\begin{tabular}{|l|l|}
\hline Original medicine & Generic \\
\hline $\begin{array}{l}\text { Module I- provided in } \\
\text { full }\end{array}$ & $\begin{array}{l}\text { Module I- provided in full } \\
\text { - Requires results of user testing of package } \\
\text { leaflet (excess requirements for generic) } \\
\text { - No clear indication when a Risk Management } \\
\text { Plan is required }\end{array}$ \\
\hline $\begin{array}{l}\text { Module II- provided } \\
\text { in full }\end{array}$ & Module II- provided in full \\
\hline $\begin{array}{l}\text { Module III - provided } \\
\text { in full }\end{array}$ & Module III - provided in full \\
\hline $\begin{array}{l}\text { Module IY- animal } \\
\text { studies }\end{array}$ & Module IY - review of preclinical data \\
\hline Module V & Module V \\
\hline $\begin{array}{l}\text { - Clinical studies } \\
\text { (I, II, III phase) }\end{array}$ & - Bioavailability/Bioequivalence \\
\hline
\end{tabular}

As a rule, comparative bioavailability primarily means studies of pharmacokinetic equivalence, that the drug enters the systemic one in an equivalent value, which can be estimated by standard pharmacokinetic parameters AUC, T, Cmax. Generic confirms its equivalence to the original medicine, provided that the Cmax and AUC values do not go beyond 80$125 \%$ of the same indicators of the original drug. However, all international documents, including the FDA and EMA, specify that comparative bioavailability, if the drug cannot be measured in the systemic circulation, in this case, pharmacodynamic equivalence studies can be used, and if it is not possible to determine pharmacodynamic points, therapeutic studies (clinical) equivalence (bioequivalence with clinical endpoints). It should be understood that Decision No. 85 refers to an expanded interpretation of comparative bioavailability. Thus, according to the requirements of Decision No. 85, the following research options are possible:

In vivo:

- Studies of pharmacokinetic equivalence (main text of the Decision No. 85)

- Studies of pharmacodynamic equivalence (Appendix 2 to Decision No. 85)

- Studies of clinical equivalence (Appendix 3 to the Decision No. 85)

In vitro:

- According to the dosage form or according to the BCS (Appendix 4 and according to the text of the Decision No. 85).

The definition of the reference medicine in Decision No. 78 is as general as possible, and according to Decision No. 85, clause 18 «When choosing a reference medicine, proceed from the following sequence:

a) An original medicinal product, the quality, safety and efficacy of which were established during registration in the Union (an original drug registered in the Union);

b) An original medicinal product registered in a state where the level of requirements for the regulation of the pharmaceutical market is not lower than the level established in the Union, if it is impossible to comply with subparagraph «a» of this paragraph;

c) A generic medicinal product registered in each of the Member States and confirming its bioequivalence to the original medicinal product (with the approval of the Expert Committee under the Commission) if it is impossible to fulfill subparagraphs «a» and «b» of this paragraph;

d) A medicinal product with at least 25 years of experience in one of the Member States (subject to approval by the Expert Committee on Medicines under the Eurasian Economic Commission) if it is impossible to comply with subparagraphs «a» - «c» of this paragraph» [15].

It is possible to use a non-original drug for equivalence studies only on the recommendation of the Expert Committee.

The definition of the EAEU reference medicine has been tightened, which is an urgent problem for generic manufacturers when choosing a reference drug for equivalence studies.

Many true originators have never been registered in the EAEU or are no longer registered. In some cases, problems arise when tracing the originator to the production site.

Combined drugs, well-studied, drugs registered on the basis of a mixed dossier, cannot be used as a reference drug. The list of reference drugs published by the Expert is not a solution to these problems.

\section{Conclusion}

The aim of the study was to compare the registration process of generic medicines and identify differences, gaps in the guidelines. Despite the fact that the prototype of the available registration procedures for medicines, including generics, in the Republic of Kazakhstan are European countries, the registration process is completely different. The rules of registration and examination of the Union establish only the general outlines of the procedure, but do not specify the procedural aspects. 
Although the Union adheres to the CTD format, the requirements for module $\mathrm{V}$ are different. There are excessive requirements for the registration dossier of a generic drug. In order to eliminate the differences in the guidelines, we need to go for harmonization. Numerous SOPs, reference manuals, templates, etc. are required for the smooth execution of various aspects of the process.

The success of public health programs in improving the health of the entire population in various aspects is due to the effectiveness of generic drug policies. Simplification of the procedure for registration of generics in the Republic of Kazakhstan can become an important tool for increasing savings from the use of generics.
Further research in this direction is important for the rational use of generics by improving access to generics for patients.

Disclosures: There is no conflict of interest for all authors.

\section{References}

1. Dylst P, Vulto A, Simoens S. Societal Value of Generic Medicines Beyond Cost-Saving Through Reduced Prices. Expert Rev Pharmacoecon Outcomes Res. 2015;15(4):701-1. https://doi.org/10.1586/14737167.2015.1017565

2. Kaliyeva D.E., Turgambayeva A.K., Kerimbayeva Z.A., Zhumambaeva S.M. Awareness of Generic Drugs Among Medical Practitioners and Patients: Literature Review. Nauka i Zdravookhranenie [Science \& Healthcare]. 2021; 5(23)5:199-207. https://doi.org/10.34689/ SH.2021.23.5.022

3. Generic Drugs. URL: https://www.who.int/medicines/areas/coordination/English Glossary.pdf (Accessed 05.09.2021)

4. Dylst P, Vulto A, Godman B, Simoens S. Generic Medicines: Solutions for a Sustainable Drug Market? Appl Health Econ Health Policy. 2013;11(5):437-43. https://doi.org/10.1007/s40258-013-0043-z

5. Generic Drugs. URL: https://www.who.int/medicines/areas/coordination/English Glossary.pdf (Accessed 05.10.2021)

6. Policy and Medicine. URL: https://www.policymed.com/2014/12/a-tough-road-cost-to-develop-one-new-drug-is-26-billion-approvalrate-for-drugs-entering-clinical-de.html (Accessed 05.09.2021)

7. Dunne S, Shannon B, Dunne C, Cullen W. A Review of the Differences and Similarities Between Generic Drugs and Their Originator Counterparts, Including Economic Benefits Associated with Usage of Generic Medicines, Using Ireland as a Case Study. BMC Pharmacol Toxicol. 2013; 14:1. https://doi.org/10.1186/2050-6511-14-1

8. WHO_TRS_996_annex09.pdf. URL: https://www.who.int/medicines/publications/pharmprep/WHO_TRS_996_annex09.pdf (Accessed 05.09.2021)

9. On Approval of the Rules for The Examination of Medicines and Medical Devices. Order of the Ministry of Health of The Republic of Kazakhstan, January 27, 2021 No. KR DSM-10. URL: https://adilet.zan.kz/rus/docs/V2100022144 (Accessed: 7.09.2021)

10. State Register of Medicines of the Republic of Kazakhstan. URL: www.ndda.kz (Accessed: 9.11.2021)

11. Unified Register of Registered Medicines of the Eurasian Economic Union. URL: https://portal.eaeunion.org/sites/commonprocesses/ ru-ru/Pages/DrugRegistrationDetails.aspx (Accessed: 13.11.2021)

12. The Centralised Procedure. URL: http://ec.europa.eu/health/authorisationprocedures-centralised_en.htm (Accessed: 11.10.2021)

13. The Mutual Recognition Procedure. URL: http://ec.europa.eu/health/authorisationprocedures-mutual-recognition_en.htm (Accessed: 11.10.2021)

14. The Decentralised Procedure. URL: http://ec.europa.eu/health/authorisationprocedures-decentralised_en.htm (Accessed: 11.10.2021)

15. On Approval of the Rules for Conducting Bioequivalence Studies of Medicinal Products Within the Framework of the Eurasian Economic Union. Decision of the Council of the Eurasian Economic Commission dated November 3, 2016 No. 85. URL: https://adilet. zan.kz/rus/docs/H16EV000085 (Accessed: 31.10.2021) 